\title{
Cerebrospinal Fluid Lumbar Tapping Utilization for Suspected Ventriculoperitoneal Shunt Under-Drainage Malfunctions
}

\author{
Jong-Beom Lee, M.D., Ho-Young Ahn, M.D., Hong-Jae Lee, M.D., Ji-Ho Yang, M.D., Jin-Seok Yi, M.D., Il-Woo Lee, M.D. \\ Department of Neurosurgery, Daejeon St. Mary's Hospital, College of Medicine (Nursing), The Catholic University of Korea, Daejeon, Korea
}

Objective : The diagnosis of shunt malfunction can be challenging since neuroimaging results are not always correlated with clinical outcomes. The purpose of this study was to evaluate the efficacy of a simple, minimally invasive cerebrospinal fluid (CSF) lumbar tapping test that predicts shunt under-drainage in hydrocephalus patients.

Methods : We retrospectively reviewed the clinical and radiological features of 48 patients who underwent routine CSF lumbar tapping after ventriculoperitoneal shunt (VPS) operation using a programmable shunting device. We compared shunt valve opening pressure and CSF lumbar tapping pressure to check under-drainage.

Results : The mean pressure difference between valve opening pressure and CSF lumbar tapping pressure of all patients were $2.21 \pm 24.57 \mathrm{mmH}_{2} \mathrm{O}$. The frequency of CSF lumbar tapping was $2.06 \pm 1.26$ times. Eighty five times lumbar tapping of 41 patients showed that their VPS function was normal which was consistent with clinical improvement and decreased ventricle size on computed tomography scan. The mean pressure difference in these patients was $-3.69 \pm 19.20 \mathrm{mmH}_{2} \mathrm{O}$. The mean frequency of CSF lumbar tapping was $2.07 \pm 1.25$ times. Fourteen cases of 10 patients revealed suspected VPS malfunction which were consistent with radiological results and clinical symptoms, defined as changes in ventricle size and no clinical improvement. The mean pressure difference was $38.07 \pm 23.58 \mathrm{mmH}_{2} \mathrm{O}$. The mean frequency of CSF lumbar tapping was $1.44 \pm 1.01$ times. Pressure difference greater than $35 \mathrm{mmH}_{2} \mathrm{O}$ was shown in $2.35 \%$ of the normal VPS function group (2 of 85 ) whereas it was shown in $64.29 \%$ of the suspected VPS malfunction group ( 9 of 14). The difference was statistically significant $(p=0.000001)$. Among 10 patients with under-drainage, 5 patients underwent shunt revision. The causes of the shunt malfunction included 3 cases of proximal occlusion and 2 cases of distal obstruction and valve malfunction.

Conclusion : Under-drainage of CSF should be suspected if CSF lumbar tapping pressure is $35 \mathrm{mmH}_{2} \mathrm{O}$ higher than the valve opening pressure and shunt malfunction evaluation or adjustment of the valve opening pressure should be made.

Key Words : Hydrocephalus · Shunt malfunction · Ventroculoperitoneal shunt · Under-drainage · Lumbar tapping.

\section{INTRODUCTION}

In communicating hydrocephalus, ventriculoperitoneal shunt (VPS) is the treatment of choice. Unfortunately, shunt malfunction within 2 years following surgery is reported up to $31 \%^{5,8)}$. The diagnosis of shunt malfunction can be chal-

- Received: April 4, 2016 • Revised: July 27, 2016 •Accepted: July 28, 2016

- Address for reprints : Jin-Seok Yi, M.D.

Department of Neurosurgery, Daejeon St. Mary's Hospital, The Catholic University of Korea, 64 Daeheung-ro, Jung-gu, Daejeon 34943, Korea

Tel : +82-42-220-9525, Fax : +82-42-222-6601, E-mail : yijinseok@hanmail.net

This is an Open Access article distributed under the terms of the Creative Commons Attribution Non-Commercial License (http://creativecommons.org/licenses/by-nc/4.0) which permits unrestricted non-commercial use, distribution, and reproduction in any medium, provided the original work is properly cited. 
lenging since neuroimaging evaluation is not always correlated with clinical outcomes. Cranial computed tomography (CT) often reveals the persistent distension of the cerebral ventricles in clinically improved patients ${ }^{9,10)}$. Invasive cerebrospinal fluid (CSF) dynamic tests have been recommended by neurosurgeons ${ }^{16)}$ to evaluate shunt malfunction.

The CSF shunt tap is another shunt malfunction diagnosis method but it still remains controversial among neurosurgeons ${ }^{13)}$. Therefore, the diagnosis of shunt malfunction remains difficult.

The purpose of this study was to evaluate a simple, minimally invasive CSF lumbar tapping test that predicts underdrainage in hydrocephalus patients with programmable valve shunting devices.

\section{MATERIALS AND METHODS}

From July 2000 to October 2007, a total of 155 patients had shunt operations using a programmable shunting device (Micro Valve with RICKHAM ${ }^{\circledast}$ Reservoir, Codman \& Shurtleff, Inc., Raynham, MA, USA). Of them, 48 patients underwent CSF lumbar tapping. Twenty patients were males and 28 patients were females. The patients's ages at implantation ranged from 21 to 78 years (mean, $58.54 \pm 14.0$ years). The etiologies of hydrocephalus included 16 cases of subarachnoid hemorrhage (SAH) after aneurysmal rupture, 21 cases of traumatic brain injury (subdural hematoma, SAH, and contusion), 8 cases of intracerebral hemorrhage and intraventricular hemorrhage (IVH), a case of tumor, a case of arteriovenous malformation and a case of moyamoya disease (Table 1). All patients had communicating type hydrocephalus. Forty-four patients had normal pressure type hydrocephalus (classified as such when lumbar or ventricular tapping pressure is $\leq 180 \mathrm{~mm} \mathrm{H}_{2} \mathrm{O}$, because the normal CSF pressure's upper limit is $180 \mathrm{mmH}_{2} \mathrm{O}$ ), and four patients had high pressure type hydrocephalus (classified as such when lumbar or ventricular tapping pressure is $>180 \mathrm{mmH}_{2} \mathrm{O}$ ). Dilated ventricles, presence of periventricular lucency, effaced cortical sulci, and presence of hydrocephalus symptoms were our indications for shunt operations. In questionable patients, we first performed a lumbar tapping test or drainage test. If there was some improvement of symptoms after daily drainage of $20 \mathrm{~mL}$ CSF for 1-3 days or daily lumbar drainage of 100-200 mL CSF for 5-7 days, VPS operation was performed.

Two to 3 weeks after the shunt operation, we evaluated the symptoms of the patients, performed CT, and used a skull Xray to rule out spontaneous resetting of the valve and routinely performed CSF lumbar tapping. We compared shunt vale opening pressure and CSF lumbar tapping pressure. Shunt malfunction was suspected by no clinical improvement or enlarged ventricle size on CT scan.

\section{CSF tapping method}

Patients were asked to lie in a supine position and bed-rested for about 30 minutes to rule out positional intracranial pressure change. Then, the position was changed to the lateral recumbent position and Tuffier's line was marked. The skin was prepared using aseptic technique and CSF tapping was performed at the level of L1-2 to L5-S1 ${ }^{1)}$.

\section{Definition of valve opening pressure and CSF lumbar tapping pressure difference}

We defined pressure difference as positive if CSF lumbar tapping pressure is higher than set valve opening pressure and negative if CSF lumbar tapping pressure is lower than set valve opening pressure.

Table 1. Patient demographics $(n=48)$

\begin{tabular}{lc}
\hline Mean age (years) & $58.54 \pm 14.0$ \\
Male/female & $20 / 28$ \\
Reason for hydrocephalus & \\
SAH & 16 \\
Traumatic brain injury & 21 \\
ICH \& IVH & 8 \\
Tumor & 1 \\
Other causes & 2 \\
\hline
\end{tabular}

$\mathrm{SAH}$ : subarachnoid hemorrhage, $\mathrm{ICH}$ : intracerebral hemorrhage, IVH : intraventricular hemorrhage 


\section{RESULTS}

A comparative analysis of 99 cases from 48 patients who had lumbar tapping after VPS operation was performed by comparing shunt valve opening pressure and lumbar tapping pressure. The mean pressure difference of all patients was $2.21 \pm 24.57 \mathrm{mmH}_{2} \mathrm{O}$. The frequency of CSF lumbar tapping was $2.06 \pm 1.26$ times.

Eighty five cases of 41 patients showed that their VPS function was normal which was consistent with clinical improvement and decreased ventricle size on CT scan. The mean pressure difference in these patients was $-3.69 \pm 19.20 \mathrm{mmH}_{2} \mathrm{O}$. The mean frequency of CSF lumbar tapping was $2.07 \pm 1.25$ times. Fourteen cases of 10 patients revealed suspected VPS malfunction which were consistent with radiological results and clinical symptoms, defined as changes in ventricle size and no clinical improvement. The mean pressure difference was $38.07 \pm 23.58 \mathrm{mmH}_{2} \mathrm{O}$. The mean frequency of CSF lumbar tapping was $1.44 \pm 1.01$ times. Of them, the VPS of 3 patients initially functioned normally but malfunction was suspected during the follow-up period. The other 7 patients showed the evidence of suspected VPS malfunction and required neurosurgical intervention. The causes of VPS malfunction included 5 cases of tube and VPS valve malfunction, 3 cases of proximal tip obstruction and 2 valve partial obstruction and distal tube obstruction. These patients underwent shunt replacement operations. Two patients who had shunt infection were treated with antibiotics and their shunts were removed. One patient had an IVH after VPS operation. Two patients who had suspected shunt malfunction by enlarged ventricle size on CT scan and no clinical improvement but refused further evaluation such as shuntography or surgical exploration. The mean pressure difference of these two groups (normal function vs. suspected malfunction) was statistically significant. In term of age, sex, mean lumbar tapping time, there were no statistically significant differences. Pressure difference greater than $35 \mathrm{mmH}_{2} \mathrm{O}$ was shown in $2.35 \%$ of the normal VPS function group (2 of 85) whereas it was shown in $64.29 \%$ of the suspected VPS malfunction group ( 9 of 14). The difference was statistically significant $(p=0.000001)$ (Table 2). Receiver operating characteristic analysis (ROC) was performed to get the best cut-off value of pressure difference. ROC analysis of pressure difference showed that the area under the curve was 0.91 and the cut-off value was 37.50 with sensitivity of $64.3 \%$ and specificity of 98.8\% (Fig. 1).

\section{Case illustration}

A 68 year old female patient with SAH due to ruptured aneurysm at right internal carotid artery and superior hypophyseal artery junction developed communicating hydrocephalus 2 months after craniotomy and aneurysm neck clipping operation. VPS operation was performed and preoperative lumbar tapping pressure was $160 \mathrm{mmH}_{2} \mathrm{O}$. The ini-

Table 2. Comparison of the characteristics in ventriculoperitoneal shunt function and suspected under-drainage malfunction group

\begin{tabular}{|c|c|c|c|}
\hline & Normal VPS function & Suspected VPS malfunction & $p$-value \\
\hline \multicolumn{4}{|c|}{ Age, years $(n=51)$} \\
\hline Mean (SD) & $58.78(15.10)$ & $57.30(10.29)$ & 0.7710 \\
\hline \multicolumn{4}{|l|}{ Gender $(n=51)$} \\
\hline Male & $19(46.3)$ & $3(30)$ & 0.4830 \\
\hline Female & $22(53.7)$ & $7(70)$ & \\
\hline \multicolumn{4}{|c|}{ CSF lumbar tapping time } \\
\hline Mean (SD) & $2.07(1.25)$ & $1.44 \pm 1.01$ & 0.1200 \\
\hline \multicolumn{4}{|c|}{ Pressure difference, $\mathrm{mmH}_{2} \mathrm{O}$} \\
\hline Mean (SD) & $-3.69(19.20)$ & $38.07(23.58)$ & 0.000001 \\
\hline
\end{tabular}

Values are numbers (percentages) for categorical variables and means (SD), median (range) others. $p$ values were calculated using the chi-square test or the wilcoxon rank sum test. VPS : ventriculoperitoneal shunt, CSF : cerebrospinal fluid 


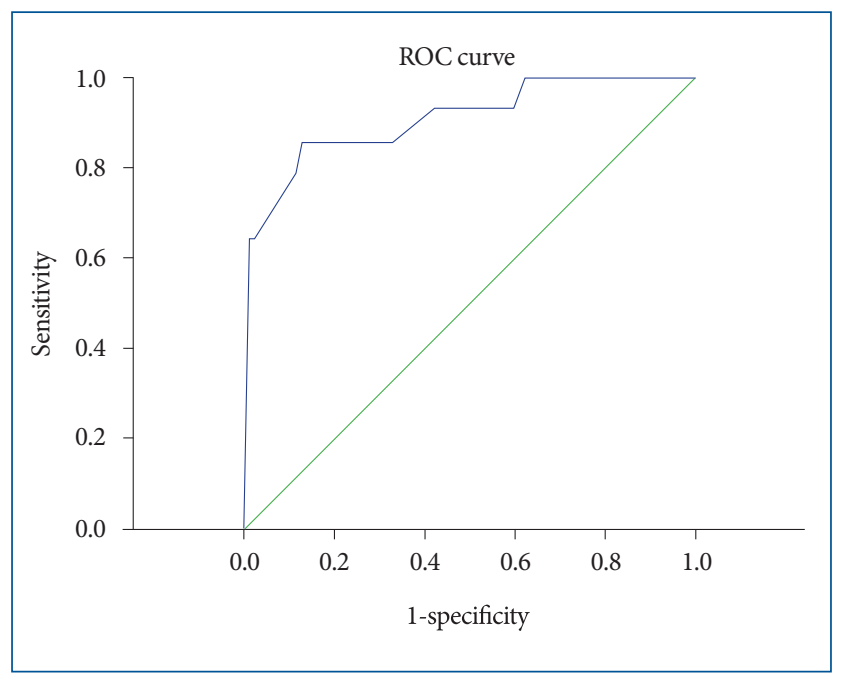

Fig. 1. Receiver operating characteristic (ROC) analysis of pressure difference. ROC analysis of pressure difference showed that the area under the curve was 0.91 and the cut-off value was 37.50 with sensitivity of $64.3 \%$ and specificity of $98.8 \%$.

tial valve opening pressure of the programmable valve was set at $130 \mathrm{mmH}_{2} \mathrm{O}$. A month after VPS operation, the patient were clinically improved partially but ventricle enlargement still remained. Her valve opening pressure was adjusted to $100 \mathrm{mmH}_{2} \mathrm{O}$. Two months after the VPS operation, the patient could not walk by herself persistently and brain CT scan showed an enlarged ventricle size and periventricular lucency. At that time the valve opening pressure was $100 \mathrm{mmH}_{2} \mathrm{O}$ and CSF lumbar tapping pressure was $155 \mathrm{mmH}_{2} \mathrm{O}$. The pressure difference was $55 \mathrm{mmH}_{2} \mathrm{O}$. We suspected shunt under-drainage or obstruction. Shuntography was done and proximal tip malfunction by partial obstruction was suspected. VPS revision was performed and partial obstruction at the proximal tip was found during the operation. We set the shunt valve opening pressure $100 \mathrm{mmH}_{2} \mathrm{O}$. Three months after shunt revision operation, she could walk by herself and CT scanning demonstrated a normal sized ventricle (Fig. 2).

\section{DISCUSSION}

Shunt malfunction after VPS operation is a common problem that leads to severe problems. If undiagnosed and left untreated, permanent neurological injury or death may oc- cur. However, the diagnosis of shunt malfunction can be challenging as neuroimaging results are not always correlated with clinical outcomes.

VPS malfunction is usually suspected if there is no clinical improvement or sustained ventriculomegaly despite of shunt valve opening pressure adjustment. CT often reveals the persistent distension of the cerebral ventricles in clinically improved patients ${ }^{9,10)}$. Alternatively normal ventricular size is not enough to rule out shunt malfunction when there is no clinical improvement ${ }^{17)}$. CSF dynamic tests are made possible through previously inserted subcutaneous reservoir prechamber type shunt valve. The results of the tests in patients underwent VPS have been proved to be effective to rule out shunt malfunction and recommended by some neurosurgeons ${ }^{9,12,16)}$. But the test remains invasive and requires special equipment as well as demands highly skilled technique ${ }^{16)}$.

Sakka et al. ${ }^{15)}$ suggested otoacoustic emission test which is a noninvasive test for VPS functionality but this test is not familiar to neurosurgeons and its efficacy is questionable. Pennell et al. ${ }^{11)}$ suggested noninvasive measurement of VPS malfunction using an ultrasonic transit time flow sensor but this procedure has not yet commercialized and requires insertion of a sensor device during VPS operation. Lumbar tapping CSF pressure measurement is an easy and less invasive test that can be used for hydrocephalus patients with programmable shunt devices.

To the authors' knowledge, this is the first study of lumbar CSF tapping pressure usage for suspected VPS under- drainage in programmable valve devices.

In our cohort, the normal VPS function group tended to show a lower CSF tapping pressure value compared to programmed shunt valve opening pressure. The pressure differences was $-3.69 \pm 19.20 \mathrm{mmH}_{2} \mathrm{O}$. Lower CSF tapping pressure value compared to the valve opening pressure is predicted over-drainage because the VPS valves we used did not have anti-siphon devices. Programmable shunting device (Micro Valve with RICKHAM ${ }^{\circledast}$ Reservoir, Codman \& Shurtleff, Inc.) was used for all patients in our study. This valve is a differential pressure valve without an anti-siphon device and drains unphysiologically high quantity of CSF $(436 \mathrm{~mL} / \mathrm{h})$ in 

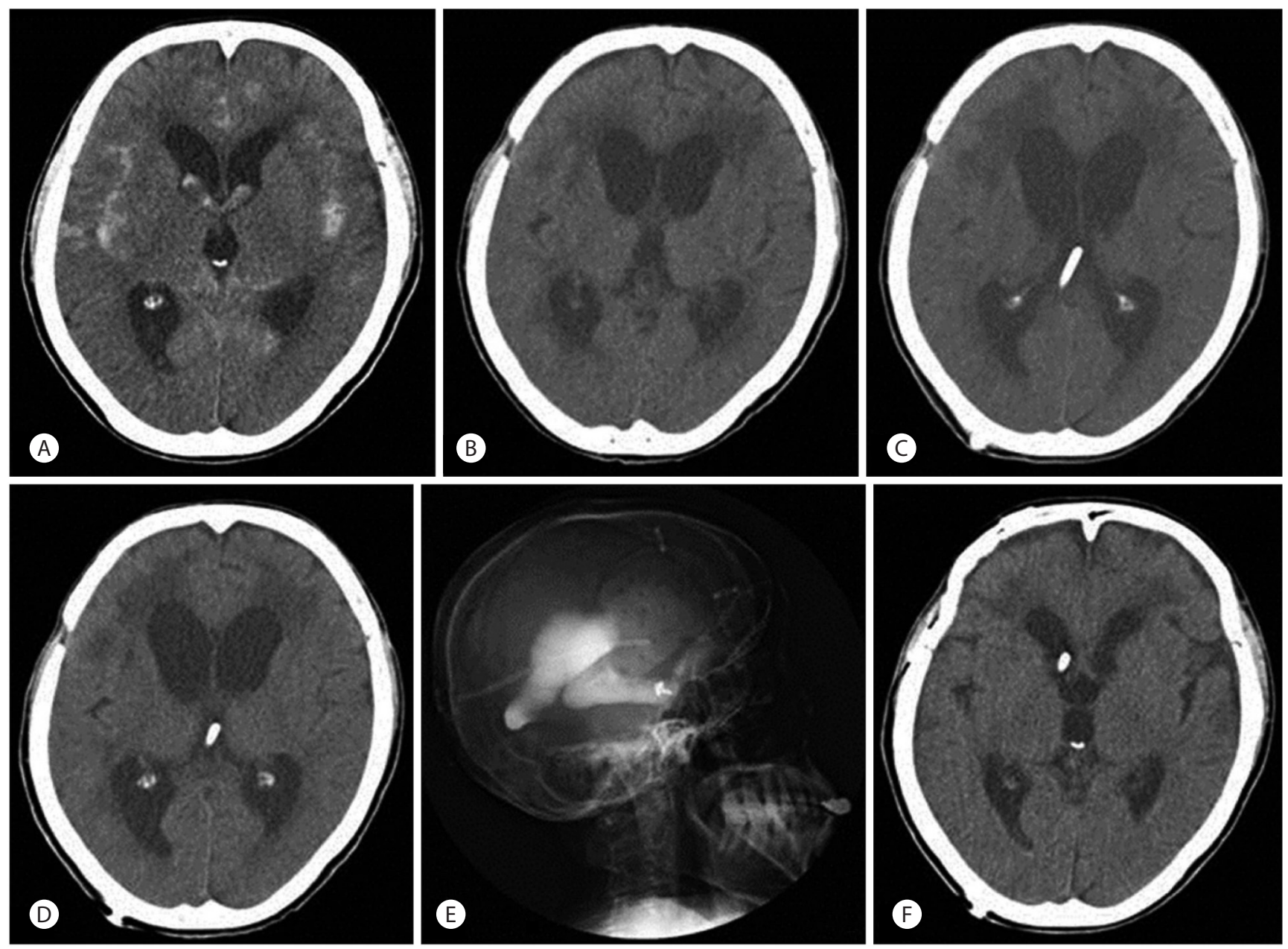

Fig. 2. Computerized tomography (CT) findings of a patient. $A$ : $C T$ at initial disease showing subarachnoid hemorrhage. $B: C T$ at 2 months after surgery after craniotomy and aneurysm neck clipping showing ventriculomegaly. C:CT at 1 month ventriculoperitoneal shunt operation showing still ventricle enlargement. D : CT at 2 month ventriculoperitoneal shunt operation showing enlarged ventricle size, developed periventricular lucency. E : Shuntography showing partial proximal tip obstruction. F : CT at 3 months after ventriculoperitoneal shunt revision operation demonstrated a normal sized ventricle.

the upright position even if the opening pressure is set at 200 $\mathrm{mmH}_{2} \mathrm{O}^{14)}$. Therefore, there is a risk or possibility of overdrainage $^{2,7)}$. In some patients, CSF lumbar tapping pressure was higher than the set valve opening pressure which suggested that either they were on bed rest or the VPS was partially functioning. Patients showing irritability or increased blood pressure due to the pain at CSF lumbar tapping procedure may be a contributing factor of a high lumbar tapping CSF pressure. Even in these cases, the pressure difference is usually same and less than $35 \mathrm{mmH}_{2} \mathrm{O}$. The two standard deviation of the pressure difference of the normal VPS function group was $34.71(-3.69 \pm 19.20) \mathrm{mmH}_{2} \mathrm{O}$. A meaningful value was shown when the pressure difference $>40 \mathrm{mmH}_{2} \mathrm{O}$. Al- though a pressure difference value of more than $20 \mathrm{mmH}_{2} \mathrm{O}$ was meaningful, $35 \mathrm{mmH}_{2} \mathrm{O}$ was determined as a cut-off value because pressure differences $20-30 \mathrm{mmH}_{2} \mathrm{O}$ were the most frequently shown in the normal VPS function group.

ROC analysis of pressure difference showed that the area under the curve was 0.91 and the cut-off value was 37.50 with specificity of $98.8 \%$. Approximate $35 \mathrm{mmH}_{2} \mathrm{O}$ was determined as a cut-off value because of lowering false positive rate at cut-off value was $37.50 \mathrm{mmH}_{2} \mathrm{O}$.

The suspected VPS malfunction group tended to show higher CSF tapping pressure values compared to their VPS valve opening pressures. The mean pressure difference was $38.07 \pm 23.58 \mathrm{mmH}_{2} \mathrm{O}$. When measured CSF lumbar tapping 
pressure was higher than the VPS valve opening pressure, this result may be inferred VPS under-drainage due to VPS malfunction, patients' positional effects or discordance between the valve opening pressure and the CSF hydrodynamics. So we lowered the valve opening pressure by $30 \mathrm{mmH}_{2} \mathrm{O}$ if patients were tolerable and showed no over-drainage symptoms. Two to 3 weeks after the adjustment of valve opening pressure, we evaluated the symptoms of the patients, performed CT, and used a skull X-ray to rule out spontaneous resetting of the valve. If the patients CT findings sustained enlarged ventricle size or there was no clinical improvement, a shuntography was performed. VPS malfunction was determined by shuntography, and the patients underwent VPS revision. Some patients showed rapid deterioration because of complete obstruction by IVH or proximal or distal obstruction or infection. Emergency VPS revision was performed for these patients.

Since Nulsen and Spitz first inserted a modern valve system in a hydrocephalus patient in 1949, fixed pressure valves have been used ${ }^{6)}$. If the valve opening pressure does not match the CSF hydrodynamics of a patient, CSF over-drainage or CSF under-drainage symptoms can develop. When using a fixed pressure valve, postoperative changes in the valve opening pressure can be accomplished only by performing another operation to insert another pressure-setting valve $^{4)}$. The use of programmable shunt devices offers many advantages in the management of patients with hydrocephalus because they are noninvasive adjustable-pressure valve systems $^{3)}$. So, in the case of over-drainage or under-drainage of CSF, surgeons can adjust the valve opening pressure by making only transcutaneous changes. In this study, a programmable shunting device without an anti-siphon device was used for all patients. Thus, the valve opening pressure could be easily adjusted according to patient symptoms; if over-drainage was suspected the valve opening pressure was elevated and under-drainage was suspected the valve opening pressure was lowered. Nevertheless, it is difficult to differentiate VPS malfunction and under-drainage because their symptoms are similar. Therefore, lumbar tapping pressure can help to diagnose shunt under-drainage. Indeed, in our case, some patients showed no clinical improvement and radiologic changes after the VPS operation, and we repeatedly lowered the valve opening pressure and misdiagnosed as shunt malfunction. Depending on adjustable valve opening pressure, it is possible to misdiagnose the VPS malfunctions. Therefore, it is suggested that under-drainage of CSF should be suspected when the pressure difference between the valve opening pressure and lumbar tapping pressure is greater than $35 \mathrm{mmH}_{2} \mathrm{O}$.

\section{Limitation}

There are several limitations in this study. Most importantly, this retrospective study was conducted by reviewing medical records, and the patients who underwent CSF lumbar tapping were only included in the analysis. Thus, it is possible that some patient with shunt malfunction may have not included. The heterogeneity and the small number of the subjects were also a limitation. Therefore, a prospective study with a larger sample is needed to draw a firm conclusion.

\section{CONCLUSION}

Lumbar tapping pressure measurement is an easy and less invasive method to diagnose VPS malfunction. In conclusion, under-drainage of CSF should be suspected if CSF lumbar tapping pressure is $35 \mathrm{mmH}_{2} \mathrm{O}$ higher than the valve opening pressure and shunt malfunction evaluation or adjustment of the valve opening pressure should be made.

\section{References}

1. Boon JM, Abrahams PH, Meiring JH, Welch T : Lumbar puncture : anatomical review of a clinical skill. Clin Anat 17 : 544-553, 2004

2. Browd SR, Gottfried ON, Ragel BT, Kestle JR : Failure of cerebrospinal fluid shunts : part II : overdrainage, loculation, and abdominal complications. Pediatr Neurol 34 : 171-176, 2006

3. Hakim S: Hydraulic and mechanical mis-matching of valve shunts used in the treatment of hydrocephalus : the need for a servo-valve shunt. Dev Med Child Neurol 15 : 646-653, 1973 
4. Han YM, Yoo DS, Kim DS, Huh PW, Cho KS, Kang JK : A clinical analysis of the ventriculoperitoneal shunt with programmable shunt divice. J Korean Neurosurg Soc 28 : 75-81, 1999

5. Hebb AO, Cusimano MD : Idiopathic normal pressure hydrocephalus : a systematic review of diagnosis and outcome. Neurosurgery 49 : 11661184; discussion 1184-1186, 2001

6. Kataria R, Kumar V, Mehta VS : Programmable valve shunts : are they really better? Turk Neurosurg $22:$ 237-238, 2012

7. Kim KH, Yeo IS, Yi JS, Lee HJ, Yang JH, Lee IW : A pressure adjustment protocol for programmable valves. J Korean Neurosurg Soc 46 : 370-377, 2009

8. Larsson A, Wikkelsö C, Bilting M, Stephensen $H$ : Clinical parameters in 74 consecutive patients shunt operated for normal pressure hydrocephalus. Acta Neurol Scand 84 : 475-482, 1991

9. Maksymowicz W, Czosnyka M, Koszewski W, Szymanska A, Traczewski $W$ : The role of cerebrospinal compensatory parameters in the estimation of functioning of implanted shunt system in patients with communicating hydrocephalus (preliminary report). Acta Neurochir (Wien) 101 : 112-116, 1989

10. Meier U, Paris S, Gräwe A, Stockheim D, Hajdukova A, Mutze $S$ : Is there a correlation between operative results and change in ventricular volume after shunt placement? A study of 60 cases of idiopathic normalpressure hydrocephalus. Neuroradiology 45 : 377-380, 2003
11. Pennell T, Yi JL, Kaufman BA, Krishnamurthy $S$ : Noninvasive measurement of cerebrospinal fluid flow using an ultrasonic transit time flow sensor : a preliminary study. J Neurosurg Pediatr 17 : 270-277, 2016

12. Petrella G, Czosnyka M, Keong N, Pickard JD, Czosnyka Z : How does CSF dynamics change after shunting? Acta Neurol Scand 118 : 182188, 2008

13. Rocque BG, Lapsiwala S, Iskandar BJ : Ventricular shunt tap as a predictor of proximal shunt malfunction in children : a prospective study. $\mathbf{J}$ Neurosurg Pediatr 1 : 439-443, 2008

14. Rohde V, Mayfrank L, Ramakers VT, Gilsbach JM : Four-year experience with the routine use of the programmable Hakim valve in the management of children with hydrocephalus. Acta Neurochir (Wien) 140 : 1127-1134, 1998

15. Sakka L, Chomicki A, Gabrillargues J, Khalil T, Chazal J, Avan P : Validation of a noninvasive test routinely used in otology for the diagnosis of cerebrospinal fluid shunt malfunction in patients with normal pressure hydrocephalus. J Neurosurg 124 : 342-349, 2016

16. Weerakkody RA, Czosnyka M, Schuhmann MU, Schmidt E, Keong N, Santarius $T$, et al. : Clinical assessment of cerebrospinal fluid dynamics in hydrocephalus. Guide to interpretation based on observational study. Acta Neurol Scand $124: 85-98,2011$

17. Winston KR, Lopez JA, Freeman J : CSF shunt failure with stable normal ventricular size. Pediatr Neurosurg 42 : 151-155, 2006 